\title{
Tai chi: an exercise that promotes optimal aging \& well-being
}

\begin{abstract}
Optimal aging and well-being is a goal of every adult. Mobility, walking speed and balance are key to maintaining functional independence, community engagement and quality of life. Tai Chi, an ancient Chinese martial art, is a mind-body exercise that influences physical, mental and social wellness. The slow, deliberate and integrated movements of Tai Chi foster effective and efficient functional movement patterns. The breadth and scope of Tai Chi research has advanced steadily since the turn of the century. Now, there is ample scientific evidence that Tai Chi fights back on the chronic diseases of aging. Its many health benefits overlap well with the leading causes of mortality and morbidity seen in older adults. Persons of all ages and abilities can perform Tai Chi. Tai Chi promotes optimal aging and well-being by providing mild-to-moderate cardiorespiratory exercise, muscular strengthening, balance and postural control along with many mental and social benefits. This paper offers the reader an outline of the who-what-where-when-why and how of Tai Chi practice to promote optimal aging and well-being for the older adult.
\end{abstract}

Keywords: quality of life, Tai Chi, older adults, walking speed, age, gender, body-massindex, quadriceps strength, balance cardiovascular health
Volume 3 Issue 6 - 2019

\section{Kristine M Hallisy}

Department of Family Medicine and Community Health, University of Wisconsin School of Medicine and Public Health, USA

Correspondence: Kristine M Hallisy, Department of Family Medicine and Community Health, Assistant Professor, Doctor of Physical Therapy Program, University of Wisconsin School of Medicine and Public Health, USA, Tel 608 263-6744, Fax 608 262-7809, Email hallisy@pt.wisc.edu

Received: August 13, 2019 | Published: November 05, 2019

\section{Introduction}

Healthy aging is a goal of every adult. Optimal aging involves wellness of mind, body and spirit. Mobility is key to maintaining independence, community engagement and quality of life. Indeed, walking speed is the 'sixth' vital sign. ${ }^{1}$ Walking speed is a robust outcome measure; it is an indicator of severity of disease as well as overall comorbid burden of illness. Walking speed is a powerful predictor of functional decline, impending frailty and risk of mortality. Many factors (e.g. age, gender, body-mass-index, quadriceps strength, balance cardiovascular health) contribute to walking speed. ${ }^{2}$ Walking speed requires antigravity support from the musculoskeletal system and keen attention to the environment. It requires sensory integration of biomechanical, neuromuscular, proprioceptive, tactile, visual and vestibular inputs to and from the central and peripheral nervous systems. ${ }^{1-3}$ Any complication due to aging, disease, deconditioning or poor lifestyle habits impacts walking speed, leg strength and balance making us less able to carry out daily tasks or respond to challenges in the environment. Tai chi (TC) is a mind-body intervention that influences walking speed and its many factors, and advances all aspects of wellness through both individual and group practice. This purpose of this paper is to outline the who-what-where-when-why and how of Tai Chi practice to promote optimal aging and well-being for the older adult (Table 1).

Table I The who-what-where-when-why and how of tai chi practice

Who can practice TC? $\quad \begin{aligned} & \text { Persons of all ages and abilities. TC can be modified from its free standing form to standing with side } \\ & \text { support or walker, or seated versions. }{ }^{4}\end{aligned}$
$\begin{aligned} & \text { What is TC? } \\ & \text { TC is a form of qigong (energy cultivation). It is an ancient Chinese martial art which fosters efficient and } \\ & \text { effective use of mental and physical energy with natural postures and movements. }{ }^{4}\end{aligned}$
Where to practice TC? $\quad \begin{aligned} & \text { Anywhere! TC requires no special equipment or clothing. Flat comfortable shoes or bare feet and a few } \\ & \text { square feet of space is all you need. }{ }^{4}\end{aligned}$
When to practice TC?
$\begin{aligned} & \text { Pick a time in your day that is best for you, and work to be consistent in your practice. TC can be a great } \\ & \text { way to start or end your day, but truly the movements of TC are so functional they can be applied to any } \\ & \text { daily task. }{ }^{4}\end{aligned}$
Why to Practice TC?
$\begin{aligned} & \text { Many chronic health conditions benefit from TC (see Table } 2 \text { ). The general health benefits of TC include: } \\ & \text { balance, aerobic capacity, muscle strength \& flexibility, cardiovascular health, bone density, emotional well- } \\ & \text { being (anxiety), chronic pain (low back pain), sleep quality and immune response. }{ }^{5}\end{aligned}$
How to practice TC?
$\begin{aligned} & \text { Multicomponent balance training }=10-15 \text { min/day with } 2-3 \text { longer sessions per week, with a goal of 3-hours } \\ & \text { of mid- to-high-level balance challenge per week for falls prevention. }{ }^{14}\end{aligned}$
of mid- to-high-level balance challenge per week for falls prevention. ${ }^{14}$ 


\section{Who can practice tai chi?}

While originally designed for young warriors, TC can be practiced by persons of all ages and abilities. Its adapted forms (e.g. simplified free standing, standing with side support or walker support or seated versions) are well suited to the older adult and designed to make TC accessible to all people. ${ }^{4}$

\section{What is tai chi?}

$\mathrm{TC}$ is a form of Qigong (energy cultivation) that originated in China $\left(13^{\text {th }}\right.$ century A.D.) as a martial art and meditation for young athletes and warriors. ${ }^{4} \mathrm{TC}$ is found in five major styles, or Chinese family lineages (e.g. Chen, Yang, Wu (Hao), Wu, and Sun), with Yang-style being the most common around the world. ${ }^{3}$ The intensity of TC can be adjusted by controlling style, speed of movement, weight separation, sustaining posture and postural height (depth of squat). The Chinese mind-body principles of TC include centering (mental focus), effective action (appropriate body mechanics) and tai chi energetics ('moving like a string of pearls' or in a coordinated fashion). ${ }^{4}$ A slow, graceful, 3-dimensional exercise, TC promotes mental awareness and postural control while building leg strength, muscular endurance and balance. ${ }^{3-5}$ Centering features awareness to the present moment and integrates exteroreceptors (data from the external environment via the eyes, eyes and tactile information from the skin) and interoreceptors (data from the vestibular system, conscious proprioceptors of the joints/ligaments, unconscious proprioceptors of the muscles and internal organs). ${ }^{4}$
Postural alignment (upright body) and slow precise movements promote proper body mechanics and safe functional 3-dimensional movements. The coordinated and balanced movements of TC promote efficiency of movement and economy of effort that is ideal for falls prevention. $^{6-8}$ It provides benefit for many chronic health conditions seen in older adults and offers psychological, social and health promotion benefits. ${ }^{5,6} \mathrm{TC}$ is a mild-to-moderate aerobic exercise depending on style (lineage) or health status of the participant. ${ }^{3}$ The flexed knee posture of TC builds muscular strength and endurance, while weight separation enhances balance and postural control. ${ }^{4}$ TC calls for mindfulness, breath awareness, postural alignment, active relaxation, slow movement, weight separation and integrated movement from the core (Dantian), all which enhance mental focus, physical strength and coordination and spiritual well-being. ${ }^{4}$

\section{Where should I practice tai chi?}

Unlike many recreational hobbies, TC requires no special location, equipment or clothing. Flat comfortable shoes or bare feet are appropriate. Simplified TC requires only a few square feet of space (approximately 3' $4^{\prime}$ '). ${ }^{4}$ Traditional TC is practice outdoors in AM when foliage is emitting optimal oxygen from overnight photosynthesis. However, practice with external support, inside on a smooth surface with tile or wood flooring lines to help foot alignment and with mirrors for visual feedback is helpful to the individual with poor kinesthetic body awareness shown in Figure 1 (A,B).
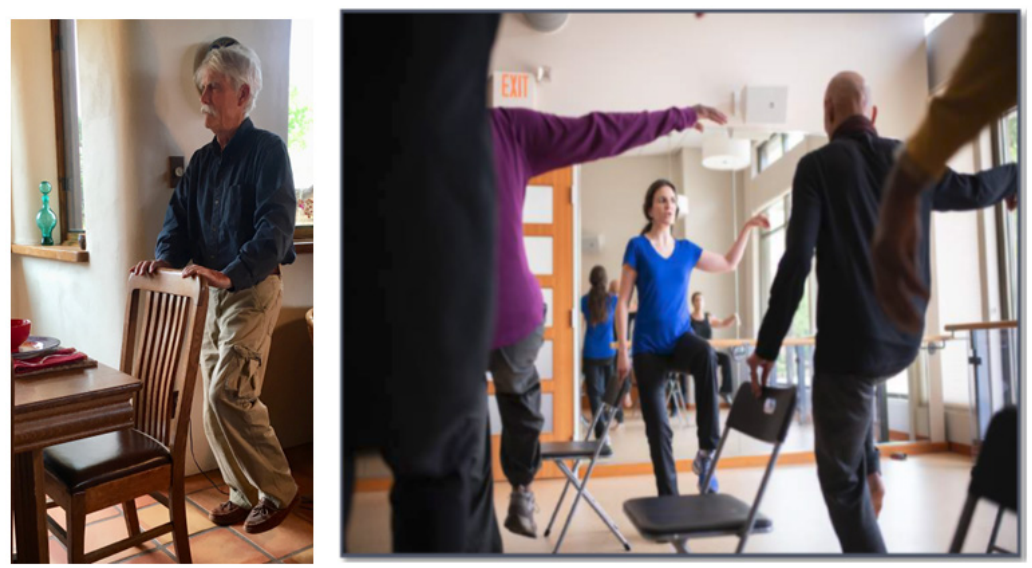

Figure I(A) Individual home practice of Tai Chi with lateral weight-shifting and progression to single leg stance with external chair support. I(B) Group TC class with optional side support and visual feedback with mirrors. ${ }^{4}$

\section{When should I practice tai chi?}

Daily TC practice is best. Scientific evidence shows no perfect time of day to exercise, but the rhythmicity of circadian cortisol may support morning exercise as the optimal time for development of healthy exercise habits. ${ }^{9}$ Historically, TC masters advocate that TC is a great way to start and end your day. ${ }^{3,4}$ In truth, all exercise works best at a time that is best for you, but simplified TC basic moves can readily be put into daily routines and become mindful, functional and restorative practice habits. ${ }^{4,10,11}$ For example, three simple TC Basic Moves from the simplified Tai Chi Fundamentals Adapted Program can be performed at the kitchen counter to enhance leg strength, balance and postural control in Figure $2(\mathrm{~A}-\mathrm{C}){ }^{4,10}$

\section{Why should I practice tai chi?}

The health benefits of TC are many (Table 2). Research suggests TC fights back on the chronic diseases of aging. ${ }^{3,5,6}$ Its many health benefits overlap well with the leading causes of mortality and morbidity seen in older adults. ${ }^{6}$ There is excellent strength of evidence for falls prevention, osteoarthritis, Parkinson's disease, chronic obstructive pulmonary disease and cognitive capacity. ${ }^{5}$ Data suggests good strength of evidence for cardiac and stroke rehabilitation, and mental health conditions including depression, stress/anxiety and cognitive impairment or dementia. ${ }^{5}$ People with chronic pain (low 
back, fibromyalgia), hypertension, osteoporosis and cancer may also benefit from TC. TC helps older adults with balance, muscle strength \& flexibility, cardiovascular health, bone density, emotional wellbeing, sleep quality and immune response., Finally, TC is safe with few studies reporting adverse events. ${ }^{12}$

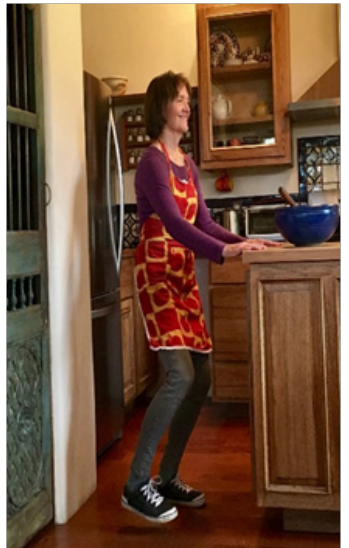

2(A) Bear roots on one leg

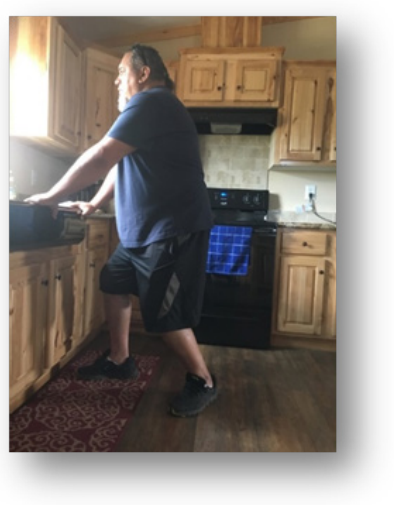

2(B) Tai chi 70/30 Stance

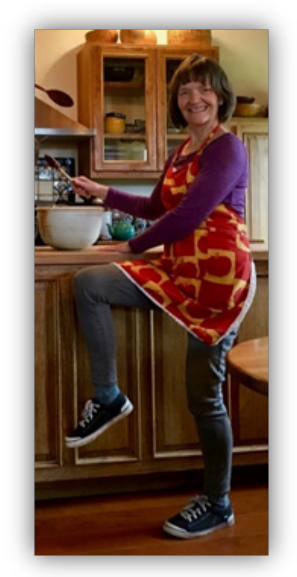

2(C) High step

Figure 2(A-C) Tai Chi at the kitchen counter: Performing Tai Chi movements throughout the day is a simple way to integrate exercise into a daily habit Three Basic Moves (Tai Chi exercises) from the Tai Chi Fundamentals Adapted Program are demonstrated. .,10 $^{4}$

Table 2 Health benefits of tai chi practice on chronic health conditions impacting older adults

\begin{tabular}{lll}
\hline Excellent evidence & Good evidence & Fair evidence \\
\hline Fall Prevention & $\cdot$ Depression & $\begin{array}{l}\cdot \text { Quality of life for } \\
\text { patients with cancer }\end{array}$ \\
. Osteoarthritis & $\begin{array}{l}\cdot \text { Cardiac } \\
\text { rehabilitation }\end{array}$ & $\cdot$ Fibromyalgia \\
Parkinson's Disease & $\begin{array}{l}\cdot \text { Stroke } \\
\text { rehabilitation } \\
\text { lung disease (COPD) }\end{array}$ & $\begin{array}{l}\text { Cognitive } \\
\text { impairment and } \\
\text { dementia }\end{array}$ \\
Cognitive capacity & \\
\hline
\end{tabular}

\section{How should I practice tai chi?}

Older adults should engage in regular exercise including aerobic conditioning (minimum of 30 minutes 5-7 days per week), strength training (8-10 muscle groups, $2 \mathrm{x} / \mathrm{week}, 70 \%$ rep max, 8-12 repetitions) and multicomponent balance activities. ${ }^{13}$ To improve balance and prevent falls, adults should practice 3-hours of mid-to high- level balance challenge exercise per week. ${ }^{14}$ Data suggest TC is most beneficial as a way to reduce fall risk when practiced for at least 50 hours cumulatively. ${ }^{15}$ This translates to taking a one-hour TC class twice a week for six months or three times a week for four months. As ongoing exercise is necessary to maintain falls protection, it is best to practice TC on a daily basis. ${ }^{14,15}$ It is optimal to have some formal $\mathrm{TC}$ training to learn the fundamentals of safe biomechanical posture and alignment, proper diaphragmatic breathing skills (relevant to all meditative movement therapies $)^{16}$ and the basic move progressions of TC. ${ }^{3,4,12}$ Fortunately, TC movements can be taught in an incremental, simple-to-complex neuromuscular progressions, allowing even the most physically and mentally challenged to benefit from this mindbody exercise. ${ }^{4}$

\section{Are you ready to adopt tai chi?}

Evidence-based TC falls prevention programs are available through the Centers of Disease Control and Prevention, ${ }^{17,18}$ National Center for Complementary and Integrative Health, ${ }^{19}$ National Council on Aging, ${ }^{15,20,21}$ Aging and Disability Resource Centers, ${ }^{22}$ YMCAs, ${ }^{23}$ health care facilities and other community partners, but more training sites are needed to help an aging American population. Physical therapists, as members of a health care team, are movement and function experts readily able to assess and implement programs that improve the ability to walk, move and function. ${ }^{24}$

\section{Summary}

TC is a meditative movement therapy that includes movement or body positioning, a focus on breathing and a calm state of mind with the goal of a deep state of relaxation. ${ }^{16} \mathrm{TC}$ is an exercise capable of meeting American College of Sports Medicine recommendations for mild-to-moderate cardiorespiratory function, muscular fitness and flexibility and neuromuscular control and agility. ${ }^{3,13} \mathrm{TC}$ is no longer an ancient Chinese secret. It is a holistic mind-body exercise capable of fostering optimal aging and well-being in the aging adult population.

\section{Acknowledgments}

None.

\section{Conflicts of interest}

The author declares there is no conflict of interest

\section{References}

1. Fritz S, Lusardi M. White paper: walking speed: the sixth vital sign. $J$ Geriatr Phys Ther. 2009;32(2):46-49.

2. Inoue $\mathrm{W}$, Ikezoe $\mathrm{T}$, Tsuboyama $\mathrm{T}$, et al. Are there different factors affecting walking speed and gait cycle variability between men and women in community-dwelling older adults? Aging Clin Exp Res. 2017;29(2):215221.

3. Lan C, Chen SY, Lai JS, et al. Tai chi chuan in medicine and health promotion. Evid Based Complement Alternat Med. 2013;2013:502131.

4. Yu T, Hallisy KM. Tai Chi Fundamentals Adapted Program with Optional Side Support, Walker Support and Seated Version. Taos, NM: Uncharted Country Publishing. 2015 
5. Huston P, McFarlane B. Health benefits of tai chi: What is the evidence? Can Fam Phys, 2016;62(11):881-890.

6. Hallisy KM. Tai chi beyond balance and fall prevention: health benefits and its potential role in combatting social isolation in the aging population. Curr Geriatr Rep. 2018;7(1):37-48.

7. Lomas-Vega R, Obrero-Gaitán E, Molina-Ortega FJ, et al. Tai Chi for Risk of Falls. A Meta-analysis. J Am Geriatr Soc. 2017;65(9):2037-2043.

8. Del-Pino-Casado R, Obrero-Gaitán E, Lomas-Vega R. The Effect of Tai Chi on Reducing the Risk of Falling: A Systematic Review and MetaAnalysis. Am J Chin Med. 2016;44(5):895-906.

9. Fournier M, d'Arripe-Longueville F, Rovere C, et al. Effects of circadian cortisol on the development of a health habit. Health Psychology. 2017;36(11):105-1064.

10. Chewning B, Hallisy KM, Mahoney J, et al. Disseminating tai chi in the community: promoting home practice and improving balance. Gerontologist. 2019;pii: gnz006.

11. Clemsom L, Fiatarone Singh MA, Bundy A, et al. Integration of balance and strength training into daily life activity to reduce rate of falls in older people (the LiFE study): Randomised parallel trial. BMJ. 2012;345:e4547.

12. Wayne PM, Berkowitz DL, Litrownik DE, et al. What do we really know about the safety of tai chi?: A systematic review of adverse event reports in randomized trials. Arch Phys Med Rehabil. 2014;95(12):2470-2483.

13. U.S. Department of Health and Human Services. Physical Activity Guidelines for Americans. $2^{\text {nd }}$ edition. Washington, DC: U.S. Department of Health and Human Services; 2018. p. 1-118.
14. Sherrington C, Michaleff ZA, Fairhall N, et al. Exercise to prevent falls in older adults: an updated systematic review and meta-analysis. Br J Sports Med. 2017;51(24):1750-1758.

15. Tai Chi for Falls Prevention. National Council on Aging. 2016. p. 1-5.

16. Larkey L, Jahnke R, Etnier J, Gonzalez J. Meditative movement as a category of exercise: implications for research. J Phys Act Health. 2009;6(2):230-238.

17. Stevens JA, Burns ER. CDC Compendium of Effective Fall Interventions: What Works for Community-Dwelling Older Adults. 3rd ed. Atlanta, GA: Centers for Disease Control and Prevention, National Center for Injury Prevention and Control, 2015.

18. About CDC's STEADI (Stopping Elderly Accidents, Deaths and Injuries) Initiative. 2019.

19. Tai Chi and Qi Gong. National Center for Complementary and Integrative Health. 2019.

20. Tai Chi: The Gateway to Active Seniors. National Council on Aging. 2019.

21. Program Summary: Tai Ji Quan: Moving for Better Balance National Council on Aging. 2019.

22. Your Fall Prevention, Aging and Disability Resource Center. 2019.

23. Moving for Better Balance. YMCA. 2019.

24. Move Forward: Physical Therapy Brings Motion to Live. American Physical Therapy Association. 2019. 